\title{
Transplantation of Mesenchymal Stem Cells Preconditioned with Hydrogen Sulfide Enhances Repair of Myocardial Infarction in Rats
}

\author{
Xinxing Xie, ${ }^{1, *}$ Aijun Sun, ${ }^{1,2, *}$ Wenqing Zhu, ${ }^{1}$ Zheyong Huang, ${ }^{1}$ Xinying Hu, ${ }^{1}$ \\ Jianguo Jia, ${ }^{1}$ Yunzeng Zou ${ }^{1,2}$ and Junbo Ge ${ }^{1,2}$ \\ ${ }^{1}$ Shanghai Institute of Cardiovascular Disease, Zhongshan Hospital, Fudan University, Shanghai, P.R. China \\ ${ }^{2}$ Institute of Biomedical Science, Fudan University, Shanghai, P.R. China
}

\begin{abstract}
Stem cell transplantation has become a promising therapeutic approach for the treatment of myocardial infarction (MI). However, the poor survival of the donor cells after transplantation has restricted its therapeutic efficacy. Hydrogen sulfide $\left(\mathrm{H}_{2} \mathrm{~S}\right)$, one gaseous signaling molecule, has been applied to inhibit cell apoptosis and promote cell survival. In the present study, we therefore examined the effects of $\mathrm{H}_{2} \mathrm{~S}$ on the survival of mesenchymal stem cells (MSCs). MSCs were isolated from the femur of male Sprague-Dawley rats (about 4 weeks old, $100 \mathrm{~g}$ ). Preconditioning MSCs with $200 \mu \mathrm{mol} / \mathrm{L}$ NaHS (as the donor of $\mathrm{H}_{2} \mathrm{~S}$ ) for 30 min decreased the hypoxia-induced cell apoptosis in vitro. The mechanisms contributing to the beneficial effects of $\mathrm{H}_{2} \mathrm{~S}$ on MSCs were associated with increased levels of phosphorylated Akt (pAkt), phosphorylated Erk1/2 (pErk1/2) and phosphorylated glycogen synthase kinase-3 $\beta$ (pGSK-3 $\beta$ ) in MSCs. Subsequently, MSCs $\left(1 \times 10^{6}\right)$, MSCs preconditioned with $\mathrm{H}_{2} \mathrm{~S}\left(1 \times 10^{6}\right)$, or phosphate buffered saline (PBS) were injected into rat hearts immediately after MI (the ligation of the left anterior descending of coronary artery). Real-time PCR for the Sry gene, located on the Y chromosome, indicated that preconditioning with $\mathrm{H}_{2} \mathrm{~S}$ improved the survival rate of the transplanted MSCs in infarcted myocardium 4 days after MI, compared with the untreated MSCs. Furthermore, transplantation of the $\mathrm{H}_{2} \mathrm{~S}$-pretreated MSCs reduced the infarct size and increased left ventricular (LV) function, as judged by transthoracic echocardiography. In conclusion, $\mathrm{H}_{2} \mathrm{~S}$ preconditioning effectively promotes MSCs survival under ischemic injury and helps cardiac repair after MI, which has great clinical significance.
\end{abstract}

Keywords: cell survival; cell transplantation; hydrogen sulfide; mesenchymal stem cells; myocardial infarction Tohoku J. Exp. Med., 2012, 226 (1), 29-36. ㅇ 2012 Tohoku University Medical Press

Cumulative experimental and clinical studies have proven the efficacy and safety of stem cell therapy in myocardial infarction (MI) (Zhang et al. 2005; Martin-Rendon et al. 2008; Hahn et al. 2008), and stem cell therapy now has been regarded as one of the most promising means to cure MI. Among several cell types used to treat MI in animal experiments, bone-marrow derived mesenchymal stem cells (MSCs) have attracted more attention and seemed to be a preferred cell source for cardiac repair because of the convenience in the isolation and expansion ex vivo (Miyahara et al. 2006; Nesselmann et al. 2008). However, the poor survival of implanted cells hampered the efficacy of cell therapy seriously; for example, Toma et al. (2002) suggested that only $0.44 \%$ of implanted cells survived in the left ventricle 4 days after transplantation and only fewer cells could be identified in the myocardium at later time points. Local ischemic environment was a key factor contributed to the high rate of stem cell death after implantation (Toma et al. 2002). Thus, it is critical to improve the survival rate of donor cells in order to enhance the therapeutic efficacy of stem cell therapy.

Hydrogen sulfide $\left(\mathrm{H}_{2} \mathrm{~S}\right)$ belongs to the growing family of the gas transmitters (Chen et al. 2007). As an endogenously-produced biological agent, $\mathrm{H}_{2} \mathrm{~S}$ plays very important roles in regulating multiple organs' functions, such as central nervous system (Kimura et al. 2005), respiratory system (Chen et al. 2011) and cardiovascular system (Calvert et al. 2010). Previous studies have demonstrated that $\mathrm{H}_{2} \mathrm{~S}$ possessed the vasorelaxant effect (Zhao and Wang 2002; Laggner et al. 2007; Bauer et al. 2010), angiogenic effect (Papapetropoulos et al. 2009) and antiatherogenic effect in Apolipoprotein E knockout mice (Wang Y. et al. 2009).

Received September 14, 2011; revision accepted for publication November 22, 2011 . doi: 10.1620/tjem.226.29

* contributed equally to this work

Correspondence: Junbo Ge, M.D., FACC, FESC, Shanghai Institute of Cardiovascular Disease, Zhongshan Hospital, Fudan University, 180 Fenglin Road, Shanghai 200032, P.R. China.

e-mail address: junboge@ 126.com 
Furthermore, in recent years, researchers focused on the cytoprotective effects of $\mathrm{H}_{2} \mathrm{~S}$ in vitro and in vivo, and found that $\mathrm{H}_{2} \mathrm{~S}$ could protect many types of cells (Yao et al. 2010; Shao et al. 2011; Taniguchi et al. 2011) from exogenous injury, though other studies indicated that $\mathrm{H}_{2} \mathrm{~S}$ could also induce cell apoptosis (Cao et al. 2006; Baskar et al. 2007). Although the cytoprotective effects of $\mathrm{H}_{2} \mathrm{~S}$ have previously been documented, its potential effect on stem cells has not been evaluated until now. Therefore, the purpose of the present study was to investigate whether preconditioning with $\mathrm{H}_{2} \mathrm{~S}$ could promote the survival of MSCs and the myocardial repair after MI using a rat model.

\section{Methods and Materials}

\section{Experimental design in vitro}

All animal experiments were performed based on the protocols approved by the Animal Care and Use Committee of Zhongshan Hospital, Fudan Uiversity. MSCs were isolated from the femur of male Sprague-Dawley rats (about 4 weeks old, $100 \mathrm{~g}$ body weight) as previously described ( $\mathrm{Li}$ et al. 2007). All cells used in the present study were at $3^{\text {rd }}-4^{\text {th }}$ passage. MSCs were injured by hypoxia for $6 \mathrm{~h}$ in serum- and glucose-free Dulbecco's Modified Eagle Medium (DMEM) as previously described (Zhu et al. 2006). Briefly, after washing with PBS, cells were placed in serum- and glucose-free DMEM and incubated in a sealed, hypoxic Anaerobic Rectacular Jar fitted with a catalyst (BioMe'rieux, Marcy l'Etoile, France, http:// www.biomerieux.com) to scavenge free oxygen.

NaHS was used as the donor of $\mathrm{H}_{2} \mathrm{~S}$. The dose and the incubation time for NaHS were determined from our preliminary experiments. MSCs were randomly assigned to one of 4 experimental groups as follows: control, non-preconditioned MSCs; $\mathrm{H}_{2} \mathrm{~S}$ group, preconditioning MSCs with $200 \mu \mathrm{mol} / \mathrm{L}$ NaHS for $30 \mathrm{~min}$; hypoxia group, non-preconditioned MSCs with hypoxic treatment as above mentioned; Hypoxia $+\mathrm{H}_{2} \mathrm{~S}$ group, preconditioning MSCs with NaHS followed by hypoxic treatment.

\section{Apoptosis assessment}

Apoptotic, necrotic, and viable MSCs in different groups were detected using the fluorescent dye PE Annexin V Apoptosis Detection Kit I (BD PharmingenTM, NJ, USA, http://www.bd.com/) according to the manufacture's instructions. Briefly, cells were rinsed with icecold PBS and then resuspended in $200 \mu \mathrm{l}$ of binding buffer. Annexin V-PE $(5 \mu \mathrm{l})$ and $5 \mu \mathrm{l}$ of 7 -amino-actinomycin D (7-AAD) were added to the cells and incubated for $15 \mathrm{~min}$ at $25^{\circ} \mathrm{C}$ in the dark. Cells were analyzed by flow cytometry within $1 \mathrm{~h}$. Ten thousands events were acquired on a FACSC-LSR (Becton-Dickinson, San Jose, CA) and analyzed with WinMDI software. Chromosomal condensation was assessed using the chromatin dye Hoechst 33342 (Beyotime, CN) under a phase contrast microscope according to the manufacture's instructions. Apoptotic cells were characterized by morphological alteration such as chromosomal condensation and nuclear shrinkage.

\section{Cell extract preparation and Western Blot analysis}

For analysis of protein levels, cells from various groups were treated with lysis buffer (RIPA buffer). The protein concentration was determined by BCA protein assay (Beyotime, $\mathrm{CN}$ ). Total proteins $(50 \mu \mathrm{g})$ were separated in $10 \%$ to $15 \%$ SDS-PAGE gels and then transferred to a polyvinylidene difluoride membrane. The membranes were blocked in $2 \%$ bovine serum albumin for $1 \mathrm{~h}$. Subsequently the blots were incubated overnight at $4{ }^{\circ} \mathrm{C}$ with antibodies specific to Akt, phosphorylated Akt (pAkt), Erk1/2, phosphorylated Erk1/2 (pErk1/2) (Cell signaling Technology, Inc. USA) and phosphorylated glycogen synthase kinase-3 $\beta$ (pGSK-3 $\beta$ ) (Bioworld Technology, Inc. USA). Antibody binding was detected with horseradish peroxidase (HRP) conjugated anti-rabbit secondary antibody, and visualized by SuperSignal West Femto and exposed to radiography film (Bio Rad). Glyceraldehyde-3-phosphate dehydrogenase (GAPDH) was used as a loading control.

A rat model of acute myocardial infarction and MSCs transplantation MI model was developed in Sprague-Dawley rats (200-250 g), as previously described (Niagara et al. 2007). The present study conforms to the Guide for the Care and Use of Laboratory Animals published by the US National Institutes of Health (NIH Publication No. 85-23, revised 1985). Just before grafting to the heart, MSCs were collected, rinsed 5 times with PBS and resuspended in PBS. The male MSCs were used for the following two series of experiments as previously described (Tang et al. 2005). The first series was designed for comparison of cardiac function and infarct size: $1.0 \times 10^{6}$ of male MSCs (MSCs group), MSCs preconditioned with $\mathrm{H}_{2} \mathrm{~S}\left(\mathrm{H}_{2} \mathrm{~S}\right.$ group) or PBS (PBS group) in $100 \mu \mathrm{l}$ of volume were intramyocardially injected into the anterior aspects of the viable myocardium bordering the infarction of the male rat heart immediately after MI with a 30 gauge needle. The second series was aimed to quantify the survival of male MSCs in the female heart by real-time PCR: $1.0 \times 10^{6}$ of MSCs (MSCs group) or MSCs preconditioned with $\mathrm{H}_{2} \mathrm{~S}\left(\mathrm{H}_{2} \mathrm{~S}\right.$ group) in $100 \mu \mathrm{l}$ of volume were injected into the myocardium of the female heart ( $n=3$ /group).

\section{Assessment of cardiac function}

LV function variables were assessed by transthoracic echocardiography 4 weeks after MI using a $17.5-\mathrm{MHz}$ phased-array transducer (Vevo 770, Visualsonics). After the induction of light general anesthesia, hearts were imaged in $2 \mathrm{D}$ and $\mathrm{M}$-mode. The recordings were obtained from parasternal long axis view at the level of the greatest LV diameter. The LV internal end-diastolic diameter (LVID,d) and LV internal end-systolic diameter (LVID,s) were measured from M-mode recordings. LV ejection fraction (LVEF) was calculated as follows: $\operatorname{LVEF}(\%)=\left[(\mathrm{LVID}, \mathrm{d})^{3}-\left(\mathrm{LVID}_{\mathrm{s}} \mathrm{s}\right)^{3}\right] /(\mathrm{LVID}, \mathrm{d})^{3} \times$ 100. The percentage of LV fractional shortening (LVFS) was calculated as follows: LVFS $(\%)=[\mathrm{LVID}, \mathrm{d}-\mathrm{LVID}, \mathrm{s}] / \mathrm{LVID}, \mathrm{d} \times 100$. All echocardiographic measurements were averaged from at least 5 separate cardiac cycles.

\section{Measurement of infarct size}

Fixed hearts were embedded in paraffin and LV cross sections were cut into $5 \mu \mathrm{m}$ slices and processed. Myocardial infarct size was determined from the intermittent heart sections cut at the mid-papillary muscle level after staining with Masson's Staining. The infarct size was defined as the sum of the epicardial and endocardial infarct circumference divided by the sum of the total LV epicardial and endocardial circumferences using computer-based planimetry.

\section{Real-time polymerase chain reaction for donor cell survival}

Real-time polymerase chain reaction (PCR) was performed for quantification of the Sry gene of donor cells after cell transplantation. The rat heart samples from different groups were frozen in liquid 
nitrogen and powdered. The genomic DNA purification was performed using Genomic DNA Isolation Kit (Tiangen) and the concentration of the purified DNA was determined by spectrophotometry. Real-time PCR was performed using Takara SYBR ${ }^{\circledR}$ Premix Ex Taq ${ }^{\mathrm{TM}}$ in a Bio-Rad iQ5 optical module. Primers for amplification of rat $\mathrm{Y}$ chromosome Sry and $\beta$-actin are listed below.

Sry: sense primer, 5'-GAG GCA CAA GTT GGC TCA ACA-3'; antisense primer, 5'-CTC CTG CAA AAA GGG CCT TT-3'. $\beta$-actin: sense primer, 5'-CCA TTG AAC ACG GCA TTG-3'; antisense primer, 5'-TAC GAC CAG AGG CAT ACA-3'. The cycling conditions were set at 30 seconds at $95^{\circ} \mathrm{C}$ for initial denaturation, 40 cycles of denaturation at $95^{\circ} \mathrm{C}$ for 5 seconds, annealing at $59.5^{\circ} \mathrm{C}$ for $30 \mathrm{sec}$ onds and extension at $72^{\circ} \mathrm{C}$ for 30 seconds. The data was acquired during the extension step. Melting curves were obtained at the end of the reaction by gradually raising the temperature by $1^{\circ} \mathrm{C} / \mathrm{min}$ from $59.5^{\circ} \mathrm{C}$ to $95^{\circ} \mathrm{C}$ over a time period of $35 \mathrm{~min}$.

\section{Statistical analysis}

Experiments were repeated at least three times. All data were described as mean \pm S.D. Statistical significance was evaluated using unpaired Student $t$ test or one-way ANOVA, where indicated. A value of $P<0.05$ was considered as statistically significant.

\section{Results}

Cytoprotective effects of preconditioning on MSCs

After the total occlusion of coronary artery, the hostile microenvironment is characterized by the lack of oxygen and nutrients, thereby leading to the death of engrafted cells. We mimicked these conditions in vitro by exposing MSCs to culture medium without glucose and serum and subjected them to hypoxic conditions. Cell death was measured using the fluorescent dye Annexin V-PE and 7-AAD. Fig. 1A showed that cell death induced by hypoxia was almost in the form of late stage of apoptosis and little in the form of early stage of apoptosis. $\mathrm{H}_{2} \mathrm{~S}$ exerted significant survival effects on both late stage of apoptosis $(9.20 \%$ vs. $17.59 \%, P<0.05)$ and early stage of apoptosis $(3.98 \%$ vs.
A

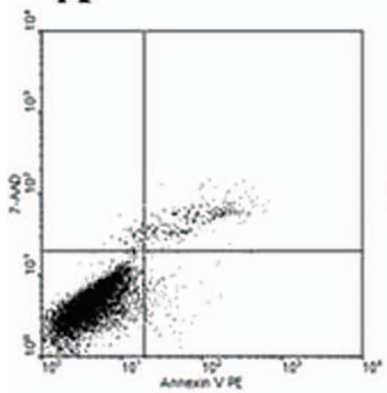

Con

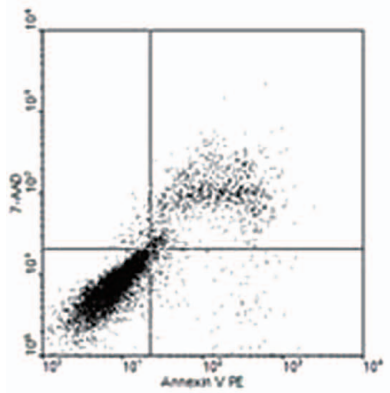

Hypoxia $+\mathrm{H}_{2} \mathrm{~S}$

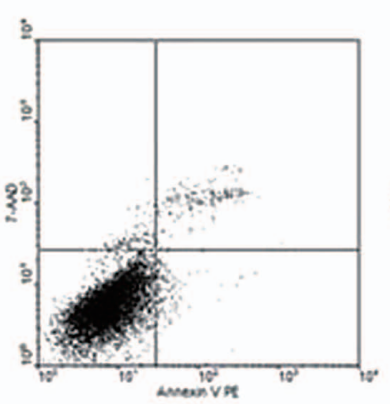

$\mathrm{H}_{2} \mathrm{~S}$

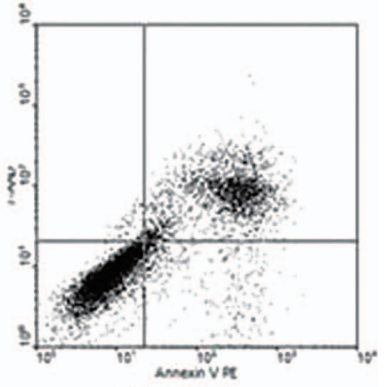

Hypoxia

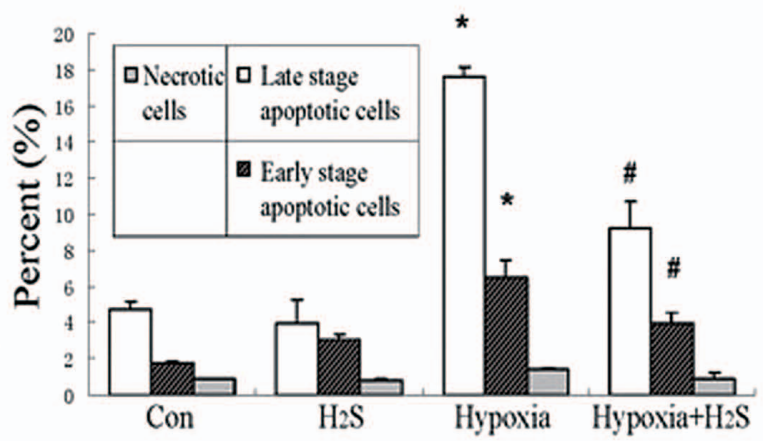

B

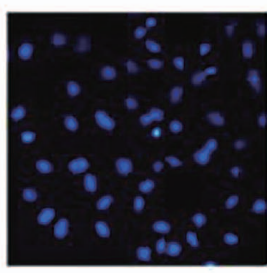

Con

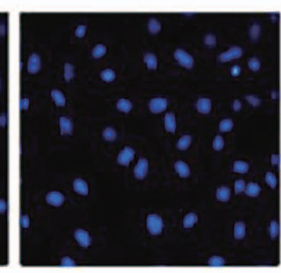

$\mathrm{H}_{2} \mathrm{~S}$

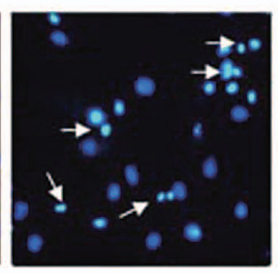

Hypoxia

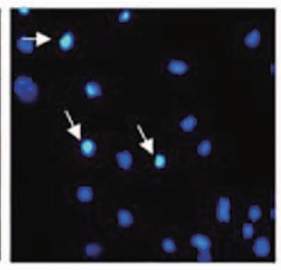

Hypoxia $+\mathrm{H}_{2} \mathrm{~S}$

Fig. 1. Preconditioning with $\mathrm{H}_{2} \mathrm{~S}$ protected hypoxia-induced cell injury.

Cell injury was determined by flow cytometry after staining with Annexin V/7-AAD and quantified using the data collected from 3 independent experiments. In scatter diagram, lower right-hand quadrant represents early stage apoptotic cells, upper right-hand quadrant is late stage apoptotic cells and necrotic cells locates in upper-left quadrant (A). Cell apoptosis was detected using phase-contrast fluorescence microscopy after Hochest 33342 staining (original magnification, $\times 200$ ), white arrows indicate apoptotic cells (B). ${ }^{*} P<0.05$ vs. control, ${ }^{\#} P<0.05$ vs. hypoxia group. 
$6.48 \%, P<0.05)$, compared with hypoxia group.

To further confirm the beneficial effect of $\mathrm{H}_{2} \mathrm{~S}$ on MSCs, we visualized the morphology of nuclei after Hochest 33342 staining. As shown in Fig. 1B, MSCs in control group had big, regular nuclei, while exposure to hypoxia resulted in chromatin condensation and nuclear shrinkage (marked with white arrows). MSCs pretreated with $\mathrm{H}_{2} \mathrm{~S}$ showed the reduced apoptotic manifestations, as compared with hypoxia group.

Preconditioning up-regulates the expression of cell survival signaling molecules in MSCs

Previous studies have suggested that PI3K/Akt and MEK/Erk $1 / 2$ are two important signaling pathways involved in cell survival (Xu et al. 2008), and the preconditioning with $\mathrm{H}_{2} \mathrm{~S}$ could induce the phosphorylation of Akt and Erk1/2 in cardiomyocytes (Hu et al. 2008), endothelial cells (Cai et al. 2007; Papapetropoulos et al. 2009), and human neuroblastoma SH-SY5Y cells (Tay et al. 2010). To explore the mechanism of cytoprotective effects of $\mathrm{H}_{2} \mathrm{~S}$ on MSCs, the intracellular phosphorylation levels of Akt and Erk1/2 were examined. After treating MSCs with $\mathrm{H}_{2} \mathrm{~S}$ for $30 \mathrm{~min}$, Western blot anaysis (Fig. 2) showed an increased phosphorylation level of Akt and Erk1/2, while no significant changes in total Akt and Erk1/2 were observed. In addition, we also investigated the effect of $\mathrm{H}_{2} \mathrm{~S}$ on the level of pGSK- $3 \beta$, which mediates anti-apoptotic effects when being inactivated by phosphorylation, and thus found that exposure to $\mathrm{H}_{2} \mathrm{~S}$ led to phosphorylation and inactivation of GSK-3 $\beta$. These results suggest that the cytoprotection of $\mathrm{H}_{2} \mathrm{~S}$ might involve the PI3K/Akt, Erk1/2 and GSK-3 $\beta$ pathways.
Effects of preconditioning on the left ventricular function and remodeling

Echocardiography results (6 animals/group) were examined 4 weeks after cell transplantation. LV function indices were summarized in Fig. 3. LVEF and LVFS in $\mathrm{H}_{2} \mathrm{~S}$ group were significantly improved $(45.35 \pm 2.25 \%$ and $23.51 \pm 1.27 \%$ ) as compared with PBS group (30.29 \pm $1.80 \%$ and $15.02 \pm 0.97 \%, P<0.01)$ and MSCs group $(36.92 \pm 0.79 \%$ and $18.79 \pm 0.47 \%, P<0.01)$. LVID,s and LVID,d, markers of LV remodeling, were significantly decreased in $\mathrm{H}_{2} \mathrm{~S}$ group (LVID,s: $6.44 \pm 0.75 \mathrm{~mm}$; LVID,d: $8.08 \pm 0.97 \mathrm{~mm}$ ) compared with PBS group (LVID,s: 8.34 $\pm 0.26 \mathrm{~mm}, P<0.01$; LVID,d: $9.87 \pm 0.43 \mathrm{~mm}, P<0.01$ ) and MSCs group (LVID,s: $7.97 \pm 0.53 \mathrm{~mm}, \mathrm{P}<0.01$; LVID,d: $9.80 \pm 0.70 \mathrm{~mm}, P<0.01$ ), though there was no statistical difference between PBS group and MSCs group.

\section{Effects of preconditioning on infarct size}

Both MSCs group and $\mathrm{H}_{2} \mathrm{~S}$ group showed significantly smaller infarct size (39.78 $\pm 3.14 \%$ in MSCs group; $30.30 \pm$ $3.37 \%$ in $\mathrm{H}_{2} \mathrm{~S}$ group) compared with the PBS group animals $(49.12 \pm 2.25 \%)$ (Fig. 4). Furthermore, the infarct size was $23.83 \%$ lower in $\mathrm{H}_{2} \mathrm{~S}$ group than that in MSCs group $(P=$ $0.000)$.

Preconditioning enhances the donor cells survival in the infarcted heart

To further verify the cytoprotective effects of preconditioning on MSCs in vivo, MSCs from male rats were injected into the female recipient hearts, and the donor cell survival was determined by real-time PCR for male rat Sry gene 4 days after transplantation as previously described (Niagara et al. 2007). The results (Fig. 5) suggested signifi-

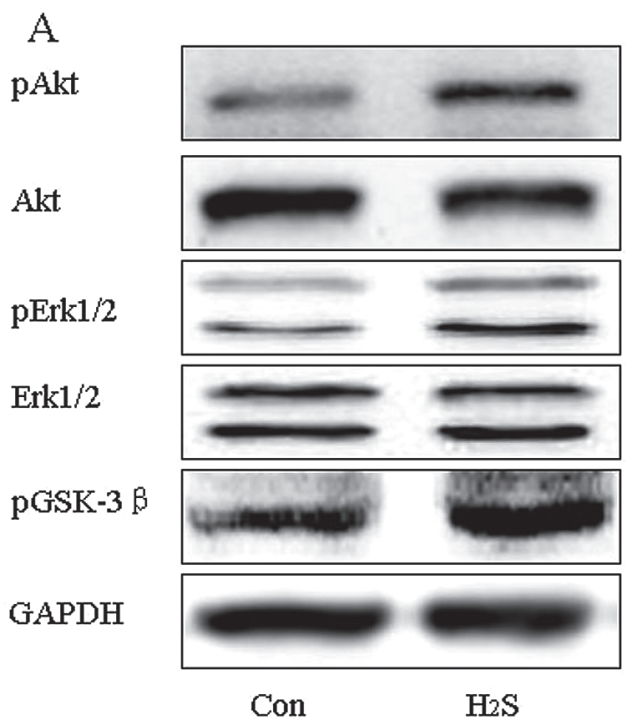

B

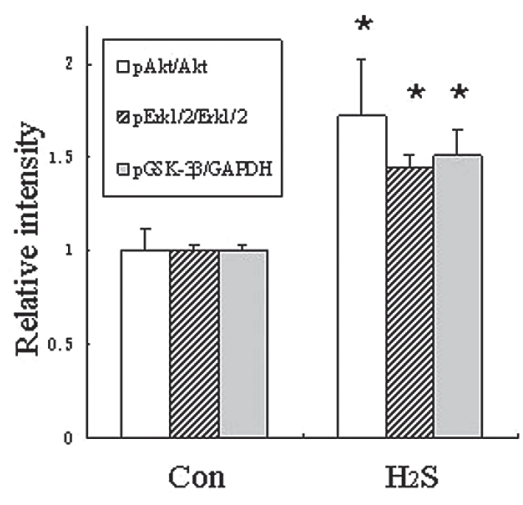

Fig. 2. Effects of preconditioning with $\mathrm{H}_{2} \mathrm{~S}$ on cell survival signaling pathway molecules and proteins. Preconditioning MSCs with $\mathrm{H}_{2} \mathrm{~S}$ could increase the intracellular level of $\mathrm{pAkt}$, pErk1/2 and pGSK-3 $\beta$. Representative blots of those proteins were shown in (A). Quantitative analysis of those proteins using data obtained from three independent experiments was shown in (B). ${ }^{*} P<0.05$ vs. control. 
A

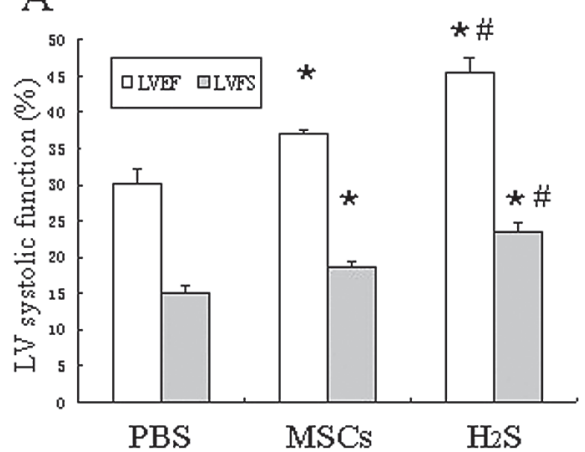

B

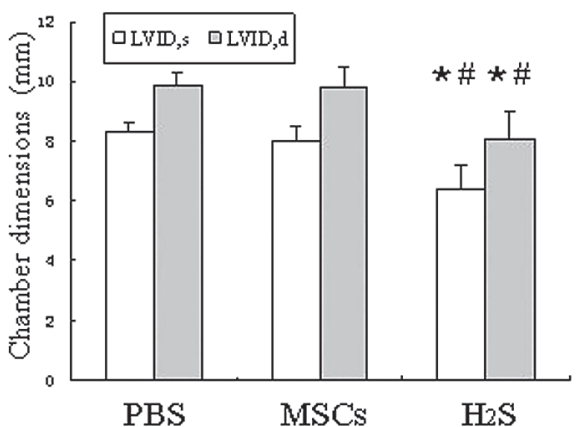

Fig. 3. Effects of MSCs transplantation on LV function indices and LV chamber dimensions. Male MSCs, MSCs preconditioned with $\mathrm{H}_{2} \mathrm{~S}$ or PBS were injected in ischemic myocardium of male rat hearts after MI. Four weeks after transplantation, transthoracic echocardiography was performed to assess the effects of therapeutic intervention on LV function indices (A) and LV chamber dimensions (B). There was significant improvement in LV function indices and LV chamber dimensions in $\mathrm{H}_{2} \mathrm{~S}$ group as compared with PBS group and MSCs group. $* P<0.05$ vs. PBS group, ${ }^{\#} P<0.05$ vs. MSCs group. LVEF: left ventricular ejection fraction, LVFS: left ventricular fractional shortening, LVID, d: left ventricular internal end-diastolic diameter, LVID,s: left ventricular internal end-systolic diameter.

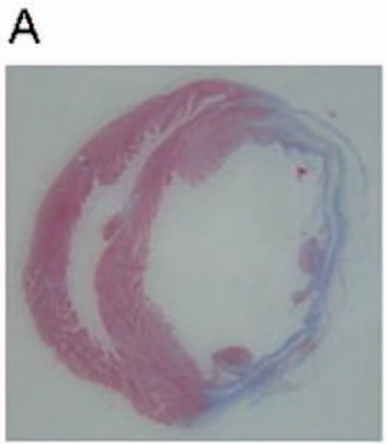

PBS

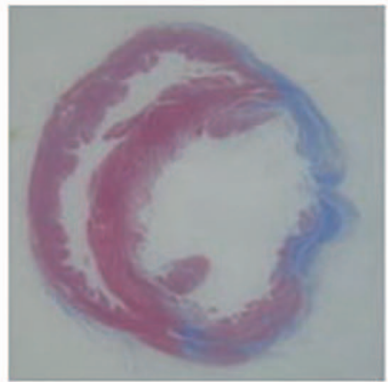

MSCs

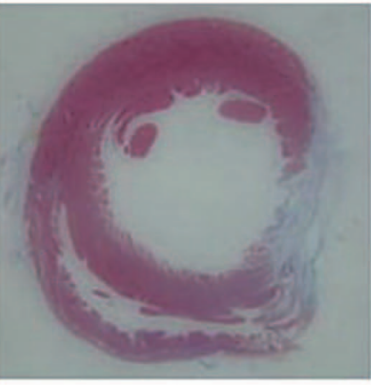

$\mathrm{H}_{2} \mathrm{~S}$

B

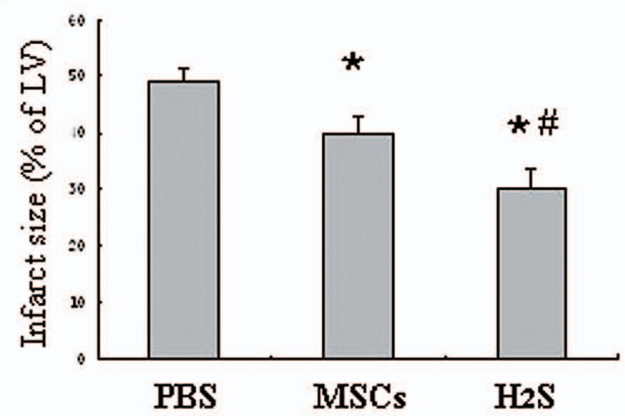

Fig. 4. Effects of preconditioning on infarct size 4 weeks after cell transplantation. After MI, male MSCs, MSCs preconditioned with $\mathrm{H}_{2} \mathrm{~S}$ or PBS were injected in the ischemic myocardium of male rat hearts. Masson staining was performed in infarcted heart sections. Representative images of Masson staining were shown in (A). Quantitative analysis of infarct size was shown in (B). ${ }^{*} P<0.05$ vs. PBS group, ${ }^{\#} P<0.05$ vs. MSCs group.

cantly higher survival of the male MSCs in $\mathrm{H}_{2} \mathrm{~S}$ group as compared with MSCs group (3 animals/group), with about 1.64-fold enhancement of donor cell survival after transplantation $(P=0.046)$.

\section{Discussion}

Cell transplantation has become a promising therapeutic strategy for ischemic heart diseases and subsequent heart failure. However, the vast majority of transplanted cells died because of death induced by the hostile environment in 


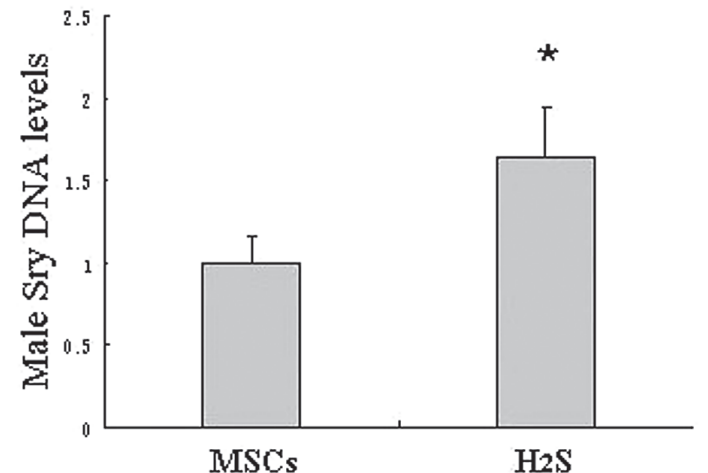

Fig. 5. Effects of preconditioning on the survival of transplanted MSCs.

After left anterior descending artery ligation, male MSCs or MSCs preconditioned with $\mathrm{H}_{2} \mathrm{~S}$ were injected in the ischemic myocardium of female rat hearts. Four days after transplantation, real-time PCR for the Sry gene showed a 1.64-fold increase in donor cell survival in $\mathrm{H}_{2} \mathrm{~S}$ group as compared with MSCs group. ${ }^{*} P<0.05$ vs. MSCs group.

ischemic myocardium (Zhang et al. 2001; Toma et al. 2002; Pagani et al. 2003), here we appraised a novel pharmacological preconditioned strategy to enhance stem cell survival after transplantation. The major findings of this study were as follows. Preconditioning with $\mathrm{H}_{2} \mathrm{~S}$ significantly promoted the survival of MSCs in vitro and in vivo; Preconditioning with $\mathrm{H}_{2} \mathrm{~S}$ markedly upregulated the levels of cell survival signaling molecules; LV function and remodeling indices were improved more significantly after transplanting MSCs preconditioned with $\mathrm{H}_{2} \mathrm{~S}$. To the best of our knowledge, the present study firstly demonstrated the potential benefits of $\mathrm{H}_{2} \mathrm{~S}$ on MSCs for cell-based therapy in ischemic heart diseases.

There were studies which indicated that high levels of cell death after transplantation were an important factor limiting the therapeutic efficacy of stem cell therapy for MI (Zhang et al. 2001; Toma et al. 2002). The reasons leading to cell death were multifactorial. Zhang et al. (2001) indicated that the transplanted cells faced an ischemic environment lacking oxygen and nutrient substance, and large amounts of donor cells died after several days of transplantation mainly due to ischemia. Furthermore, host inflammatory response, loss of survival signals and masses of proapoptotic or cytotoxic factors in infarcted myocardium might also contribute to cell death. Over recent years, much attention was put on strategies to ameliorate cell survival after transplantation. There were studies suggested that genetically modified MSCs by some protective genes such as Akt (Gnecchi et al. 2006), Bcl-2 (Li et al. 2007), and HSP-20 (Wang X. et al. 2009) could enhance the donor cell survival and improve cardiac function. Exogenous manipulation of stem cells with chemical treatments (especially drugs) also had salutary effects for donor cell survival and host cardiac function after MI (Niagara et al. 2007; Wisel et al. 2009). Obviously, the latter had its unique advantages compared with genetic engineering. It was easily achieved, more economical, and less ethical and safety considerations; it had great clinical relevance especially when pretreating stem cells with drugs which were still not used in clinical practice such as $\mathrm{H}_{2} \mathrm{~S}$ in our study.

$\mathrm{H}_{2} \mathrm{~S}$ is an important signaling molecule with multiple biological properties. The salutary effects of $\mathrm{H}_{2} \mathrm{~S}$ have been investigated in the heart and other organs (Calvert et al. 2010; Chen et al. 2011). The main purpose of present study was to investigate the effectiveness of $\mathrm{H}_{2} \mathrm{~S}$ for protection of MSCs against hypoxia-induced cell injury. Indeed, we found an obvious improvement in MSCs' viability under hypoxic conditions after preconditioning with $\mathrm{H}_{2} \mathrm{~S}$ in vitro and in vivo. Based on the Sry gene detection, cell survival in $\mathrm{H}_{2} \mathrm{~S}$ group was 1.64-fold as compared with non-preconditioned MSCs group at 4 days after MI. To some extent more survived cells always meant better local cardiac microenvironment and more trophic effects on damaged heart (Gnecchi et al. 2005; Niagara et al. 2007). In other words, preconditioning was more time-saving and economic compared to propagation of MSCs to a lager number. All these had great clinical significance.

In our study, $\mathrm{H}_{2} \mathrm{~S}$ could increase the levels of pAkt, pErk1/2 and pGSK-3 $\beta$, which were important cell survival pathways and mediated the cytoprotective effects in various cell types including MSCs. So it was reasonable to think that these changes of cell survival-related molecules contributed to the cytoprotective effects of $\mathrm{H}_{2} \mathrm{~S}$ on MSCs.

The impact of MSCs transplantation on cardiac regeneration was not investigated in this study because of the following reasons. (1) Current studies indicated that MSCs had a relatively low differentiation ratio to cardiomyocytes, and trans-differentiation might not account for major protection of ischemic heart by MSCs (Alvarez-Dolado et al. 2003; Gnecchi et al. 2006; Rose et al. 2008). (2) One study indicated that MSCs experienced a transition from an immunoprivileged state to an immunogenic state after transplantation, and thus, they could be eliminated by the host after differentiation (Huang et al. 2010).

In summary, $\mathrm{H}_{2} \mathrm{~S}$ preconditioning showed a dramatical protection from hypoxia induced cell death in MSCs, which was accompanied by significant increased phosphorylation levels of Akt, Erk1/2 and GSK-3 $\beta$. As a result, transplantation of $\mathrm{H}_{2} \mathrm{~S}$-preconditioned MSCs created more significant improvement of cardiac function and attenuation of LV remodeling. Considering the great potential of drugs elevating endogenous levels of $\mathrm{H}_{2} \mathrm{~S}$ in clinical practice (Predmore and Lefer 2010), stem cell therapy combined with $\mathrm{H}_{2} \mathrm{~S}$ would have great clinical relevance in cell-based therapy for ischemic heart diseases.

\section{Acknowledgments}

The authors gratefully acknowledge the financial support from the National Natural Science Foundation of China (No. 81000043) and the Youth Foundation of Zhongshan Hospital. We also thank Dr. Kai Hu from Wuerzburg University in 
Germany for assistance with the preparation of this manuscript.

\section{Conflict of Interest}

All authors declare no conflict of interest.

\section{References}

Alvarez-Dolado, M., Pardal, R., Garcia-Verdugo, J.M., Fike, J.R., Lee, H.O., Pfeffer, K., Lois, C., Morrison, S.J. \& Alvarez-Buylla, A. (2003) Fusion of bone-marrow-derived cells with Purkinje neurons, cardiomyocytes and hepatocytes. Nature, 425, 968-973.

Baskar, R., Li, L. \& Moore, P.K. (2007) Hydrogen sulfide-induces DNA damage and changes in apoptotic gene expression in human lung fibroblast cells. FASEB J., 21, 247-255.

Bauer, C.C., Boyle, J.P., Porter, K.E. \& Peers, C. (2010) Modulation of $\mathrm{Ca}^{2+}$ signalling in human vascular endothelial cells by hydrogen sulfide. Atherosclerosis, 209, 374-380.

Cai, W.J., Wang, M.J., Moore, P.K., Jin, H.M., Yao, T. \& Zhu, Y.C. (2007) The novel proangiogenic effect of hydrogen sulfide is dependent on Akt phosphorylation. Cardiovasc. Res., 76, $29-40$.

Calvert, J.W., Coetzee, W.A. \& Lefer, D.J. (2010) Novel insights into hydrogen sulfide-mediated cytoprotection. Antioxid. Redox. Signal., 12, 1203-1217.

Cao, Y., Adhikari, S., Ang, A.D., Moore, P.K. \& Bhatia, M. (2006) Mechanism of induction of pancreatic acinar cell apoptosis by hydrogen sulfide. Am. J. Physiol. Cell. Physiol., 291, C503C510.

Chen, C.Q., Xin, H. \& Zhu, Y.Z. (2007) Hydrogen sulfide: third gaseous transmitter, but with great pharmacological potential. Acta Pharmacol. Sin., 28, 1709-1716.

Chen, Y.H., Wang, P.P., Wang, X.M., He, Y.J., Yao, W.Z., Qi, Y.F. \& Tang, C.S. (2011) Involvement of endogenous hydrogen sulfide in cigarette smoke-induced changes in airway responsiveness and inflammation of rat lung. Cytokine, 53, 334-341.

Gnecchi, M., He, H., Liang, O.D., Melo, L.G., Morello, F., Mu, H., Noiseux, N., Zhang, L., Pratt, R.E., Ingwall, J.S. \& Dzau, V.J. (2005) Paracrine action accounts for marked protection of ischemic heart by Akt-modified mesenchymal stem cells. Nat. Med., 11, 367-368.

Gnecchi, M., He, H., Noiseux, N., Liang, O.D., Zhang, L., Morello, F., Mu, H., Melo, L.G., Pratt, R.E., Ingwall, J.S. \& Dzau, V.J. (2006) Evidence supporting paracrine hypothesis for Aktmodified mesenchymal stem cell-mediated cardiac protection and functional improvement. FASEB J., 20, 661-669.

Hahn, J.Y., Cho, H.J., Kang, H.J., Kim, T.S., Kim, M.H., Chung, J.H., Bae, J.W., Oh, B.H., Park, Y.B. \& Kim, H.S. (2008) Pretreatment of mesenchymal stem cells with a combination of growth factors enhances gap junction formation, cytoprotective effect on cardiomyocytes, and therapeutic efficacy for myocardial infarction. J. Am. Coll. Cardiol., 51, 933-943.

Hu, Y., Chen, X., Pan, T.T., Neo, K.L., Lee, S.W., Khin, E.S., Moore, P.K. \& Bian, J.S. (2008) Cardioprotection induced by hydrogen sulfide preconditioning involves activation of ERK and PI3K/Akt pathways. Pflugers Arch., 455, 607-616.

Huang, X.P., Sun, Z., Miyagi, Y., McDonald Kinkaid, H., Zhang, L., Weisel, R.D. \& Li, R.K. (2010) Differentiation of allogeneic mesenchymal stem cells induces immunogenicity and limits their long-term benefits for myocardial repair. Circulation, 122, 2419-2429.

Kimura, H., Nagai, Y., Umemura, K. \& Kimura, Y. (2005) Physiological roles of hydrogen sulfide: synaptic modulation, neuroprotection, and smooth muscle relaxation. Antioxid. Redox. Signal., 7, 795-803.

Laggner, H., Hermann, M., Esterbauer, H., Muellner, M.K., Exner, M., Gmeiner, B.M. \& Kapiotis, S. (2007) The novel gaseous vasorelaxant hydrogen sulfide inhibits angiotensin-converting enzyme activity of endothelial cells. J. Hypertens., 25, 2100-
2104.

Li, W., Ma, N., Ong, L.L., Nesselmann, C., Klopsch, C., Ladilov, Y., Furlani, D., Piechaczek, C., Moebius, J.M., Lützow, K., Lendlein, A., Stamm, C., Li, R.K. \& Steinhoff, G. (2007) Bcl-2 engineered MSCs inhibited apoptosis and improved heart function. Stem Cells, 25, 2118-2127.

Martin-Rendon, E., Brunskill, S.J., Hyde, C.J., Stanworth, S.J., Mathur, A. \& Watt, S.M. (2008) Autologous bone marrow stem cells to treat acute myocardial infarction: a systematic review. Eur. Heart J., 29, 1807-1818.

Miyahara, Y., Nagaya, N., Kataoka, M., Yanagawa, B., Tanaka, K., Hao, H., Ishino, K., Ishida, H., Shimizu, T., Kangawa, K., Sano, S., Okano, T., Kitamura, S. \& Mori, H. (2006) Monolayered mesenchymal stem cells repair scarred myocardium after myocardial infarction. Nat. Med., 12, 459-465.

Nesselmann, C., Ma, N., Bieback, K., Wagner, W., Ho, A., Konttinen, Y.T., Zhang, H., Hinescu, M.E. \& Steinhoff, G. (2008) Mesenchymal stem cells and cardiac repair. J. Cell. Mol. Med., 12, 1795-1810.

Niagara, M.I., Haider, H., Jiang, S. \& Ashraf, M. (2007) Pharmacologically preconditioned skeletal myoblasts are resistant to oxidative stress and promote angiomyogenesis via release of paracrine factors in the infarcted heart. Circ. Res., 100, 545-555.

Pagani, F.D., DerSimonian, H., Zawadzka, A., Wetzel, K., Edge, A.S., Jacoby, D.B., Dinsmore, J.H., Wright, S., Aretz, T.H., Eisen, H.J. \& Aaronson, K.D. (2003) Autologous skeletal myoblasts transplanted to ischemia-damaged myocardium in humans. Histological analysis of cell survival and differentiation. J. Am. Coll. Cardiol., 41, 879-888.

Papapetropoulos, A., Pyriochou, A., Altaany, Z., Yang, G., Marazioti, A., Zhou, Z., Jeschke, M.G., Branski, L.K., Herndon, D.N., Wang, R. \& Szabó, C. (2009) Hydrogen sulfide is an endogenous stimulator of angiogenesis. Proc. Natl. Acad. Sci. USA, 106, 21972-21977.

Predmore, B.L. \& Lefer, D.J. (2010) Development of hydrogen sulfide-based therapeutics for cardiovascular disease. $J$. Cardiovasc. Transl. Res., 3, 487-498.

Rose, R.A., Jiang, H., Wang, X., Helke, S., Tsoporis, J.N., Gong, N., Keating, S.C., Parker, T.G., Backx, P.H. \& Keating, A. (2008) Bone marrow-derived mesenchymal stromal cells express cardiac-specific markers, retain the stromal phenotype, and do not become functional cardiomyocytes in vitro. Stem cells, 26, 2884-2894.

Shao, J.L., Wan, X.H., Chen, Y., Bi, C., Chen, H.M., Zhong, Y., Heng, X.H. \& Qian, J.Q. (2011) $\mathrm{H}_{2} \mathrm{~S}$ protects hippocampal neurons from anoxia-reoxygenation through cAMP-mediated PI3K/Akt/p70S6K cell-survival signaling pathways. J. Mol. Neurosci., 43, 453-460.

Tang, Y.L., Tang, Y., Zhang, Y.C., Qian, K., Shen, L. \& Phillips, M.I. (2005) Improved graft mesenchymal stem cell survival in ischemic heart with a hypoxia-regulated heme oxygenase-1 vector. J. Am. Coll. Cardiol., 46, 1339-1350.

Taniguchi, S., Kang, L., Kimura, T. \& Niki, I. (2011) Hydrogen sulphide protects mouse pancreatic beta-cells from cell death induced by oxidative stress, but not by endoplasmic reticulum stress. Br. J. Pharmacol., 162, 1171-1180.

Tay, A.S., Hu, L.F., Lu, M., Wong, P.T. \& Bian, J.S. (2010) Hydrogen sulfide protects neurons against hypoxic injury via stimulation of ATP-sensitive potassium channel/protein kinase C/extracellular signal-regulated kinase/heat shock protein 90 pathway. Neuroscience, 167, 277-286.

Toma, C., Pittenger, M.F., Cahill, K.S., Byrne, B.J. \& Kessler, P.D. (2002) Human mesenchymal stem cells differentiate to a cardiomyocyte phenotype in the adult murine heart. Circulation, 105, 93-98.

Wang, X., Zhao, T., Huang, W., Wang, T., Qian, J., Xu, M., Kranias, E.G., Wang, Y. \& Fan, G.C. (2009) Hsp20-engineered mesenchymal stem cells are resistant to oxidative stress 
via enhanced activation of Akt and increased secretion of growth factors. Stem Cells, 27, 3021-3031.

Wang, Y., Zhao, X., Jin, H., Wei, H., Li, W., Bu, D., Tang, X., Ren, Y., Tang, C. \& Du, J. (2009) Role of hydrogen sulfide in the development of atherosclerotic lesions in apolipoprotein $\mathrm{E}$ knockout mice. Arterioscler. Thromb. Vasc. Biol., 29, 173-179.

Wisel, S., Khan, M., Kuppusamy, M.L., Mohan, I.K., Chacko, S.M., Rivera, B.K., Sun, B.C., Hideg, K. \& Kuppusamy, P. (2009) Pharmacological preconditioning of mesenchymal stem cells with trimetazidine (1-[2,3,4-trimethoxybenzyl] piperazine) protects hypoxic cells against oxidative stress and enhances recovery of myocardial function in infarcted heart through Bcl-2 expression. J. Pharmacol. Exp. Ther, 329, 543-550.

Xu, R., Chen, J., Cong, X., Hu, S. \& Chen, X. (2008) Lovastatin protects mesenchymal stem cells against hypoxia- and serum deprivation-induced apoptosis by activation of PI3K/Akt and ERK1/2. J. Cell. Biochem., 103, 256-269.

Yao, L.L., Huang, X.W., Wang, Y.G., Cao, Y.X., Zhang, C.C. \&
Zhu, Y.C. (2010) Hydrogen sulfide protects cardiomyocytes from hypoxia/reoxygenation-induced apoptosis by preventing GSK-3beta-dependent opening of mPTP. Am. J. Physiol. Heart Circ. Physiol., 298, H1310-H1319.

Zhang, M., Methot, D., Poppa, V., Fujio, Y., Walsh, K. \& Murry, C.E. (2001) Cardiomyocyte grafting for cardiac repair: graft cell death and anti-death strategies. J. Mol. Cell. Cardiol., 33, 907-921.

Zhang, S., Jia, Z., Ge, J., Gong, L., Ma, Y., Li, T., Guo, J., Chen, P., Hu, Q., Zhang, P., Liu, Y., Li, Z., Ma, K., Li, L. \& Zhou, C. (2005) Purified human bone marrow multipotent mesenchymal stem cells regenerate infarcted myocardium in experimental rats. Cell Transplant., 14, 787-798.

Zhao, W. \& Wang, R. (2002) $\mathrm{H}_{2} \mathrm{~S}$-induced vasorelaxation and underlying cellular and molecular mechanisms. Am. J. Physiol. Heart. Circ. Physiol., 283, H474-H480.

Zhu, W., Chen, J., Cong, X., Hu, S. \& Chen, X. (2006) Hypoxia and serum deprivation-induced apoptosis in mesenchymal stem cells. Stem Cells, 24, 416-425. 